\title{
Impact of Population Growth on Economic Growth in Africa: A Dynamic Panel Data Approach (1980 -2015)
}

\author{
Amade Peter ${ }^{1}$ and Ibrahim H. Bakari ${ }^{2}$ \\ ${ }^{1}$ Department of Economics, Adamawa State University, Mubi. \\ ${ }^{2}$ Department of Economics, Modibbo Adama University of Technology, Yola. \\ Email: amadepeter13@gmail.com
}

\begin{abstract}
This study examines the impact of population growth on the economic growth of African countries using panel data approach from 1980 -2015. The impact of population growth on economic growth is still largely controversial at national and regional levels. The study used annual secondary data of fifty three (53) African countries sourced from the World Development Indicators database. Data were collected for economic growth, proxied by GDP, population growth, fertility rate, crude death rate and inflation rate. The data were analyzed using descriptive statistics, as well as dynamic panel models of difference and system GMM. The results of the difference and system GMM suggest that population growth exerts a positive impact on economic growth of Africa while fertility has a negative impact on economic growth of Africa. The paper concludes and recommends that population growth impacts positively on economic growth and thus African countries should adopt and implement pragmatic policy measures that will enhance the productivity of its population so as to reap more demographic dividends.
\end{abstract}

Keywords: Population Growth, Fertility Rate, System GMM, Difference GMM, Economic Growth

JEL Classification Codes: J11, J13, C33, O40

\section{Introduction}

Africa is the fastest growing major area in the world, with the population predicted to reach 2.4 billion in 2050 from 1.1 billion today (UN, 2015). Consequently, more than half of the people predicted to be added to the global population between now and 2050 will be born in Africa. It should be noted that population growth in the region is projected even though families are likely to choose to have fewer children in the future. This is due to the current age 
structure of Africa's population, with a large number of young people still to reach their reproductive years (Hall, Dawson, MacDiarmid, Matthews and Smith, 2017).

The impact of population growth rate on economic growth has been a subject of controversial empirical debate since the publication of Malthus' work on population. The debate has swung in both directions - with Malthus supporter advocating population control measures due to its negative impact on growth, and his critics arguing that advancement in science and technology in the field of agriculture will cushion the negative impact of population growth on economic growth. There seem to be some misconceptions on the issues of population growth that are pertinent to the developing world. First is the belief that fertility declines already under way in Asia and Latin America would soon occur in Africa. Second is the belief that high AIDS mortality would halt population growth in Sub-Sahara Africa, among others (Bongaarts and O'Niell, 2018).

However, the African continent is the poorest continent in the world (Ndambiri, Ritho, Nga'anga, Kubowon, Mairura, Nyangweso, Muiriri and Cherotwo, 2012). Its population is also the fastest growing among other continents with a natural rate of population growth of 2.5\%; while Asia at 1.1\%, Europe 0.40\%, Latin America and Caribbean 1.2\% (UN, 2014). Statistically, West Africa had a real per-capita growth rate of -0.011 , while Southern Africa had 0.05. An average population growth rate of 2.7 in West Africa compares to 2.2 in Southern Africa; a life expectancy of 46.68 in West Africa compares to 51.15 in Southern Africa between 1970 and 2005 (Akintunde, Olomola and Oladeji, 2013). Thus the West African region has a lot to do to improve economically. From the 1960s, many developing countries have experienced a significant fertility decline in line with the demographic transition, but in Africa, the decline has been largely slow and in some cases there has been a stall in fertility rates (Mekonen, 2011). This fertility trend may not be unconnected to the high population growth rate of the continent among others.

Population growth may have several diverse effects on the growth and performance of a nation. While the populations of China (1.38 billion) and India (1.31 billion), home to more than half of the world population have recorded an average growth rate of 4-5\% annually from 2001, they have equally been entrapped by the Malthusian population trap. Standard of living is higher when the population is low, but when population large, the standard of living will be low (UNPD, 2015, Lozeau, 2007).

The 1990s and 2000s saw growing concerns about population in scientific, policy, and public arenas. However, a number of factors converged to downplay ecological and 
socioeconomic issues related to population growth. A globally declining fertility rate promoted a widespread perception that the population problem was on the way to solving itself. Moreover, the interaction between an aging population and low fertility rates in some developed nations has generated concerns that a shrinking workforce might adversely affect public finances and standards of living; however, the reverse remains the case for developing countries (Crist, Mora and Engelman, 2017).

The positive impact of population on economic growth depends on the age structure of the population, however, its negative impact depends less on the age structure of the population (Prskawetz and Lindh, 2007).Bloom, Canning and Malaney (1999) found out that population growth as a whole has a negative impact on economic growth, while growth of the working population has a strong positive impact on economic growth; however, this conclusion may not be observable across all countries. Thus there is indefinite conclusion on the impact of population growth on economic growth of countries and regions. This necessitates further studies on the impact for regional economies such as Africa considering its economic backwardness and high population growth rates.

Although there is a dearth of existing studies on the impact of population growth on economic growth using panel data method in the African context. However, notable studies have been conducted on the impact of population and population dynamics on Sub-Sahara Africa (Akintunde, et al 2013); on some developing countries (Hamza, 2015) and Chang, Chu, Deale, and Gupta (2015). These studies used different methodologies, time coverage, and arrived at different findings. However, none of these studies was conducted on all the countries of Africa. Thus the main trust of this article is to determine the impact of population growth on economic growth in Africa from 1980-2015. The study starts from 1980 due to a high tendency of non-availability of data of African countries prior to 1980 and also because a handful of countries gained their independence between 1970 -1990.Fifty three (53) countries in Africa were included in the analysis except South Sudan which only gained independence in 2011.

\section{Literature Review}

The Malthusian theory of population has sparked so much debate in the economic parlance regarding the relationship between population and economic growth. Ensuing from the population debates are three popular views regarding the population-economic growth nexus. First, the 'population pessimists' who support the Malthusian thought about the effect of population growth on economic growth. The pessimists assert that the world has yet to 
prove that it can use technology to overcome natural resource limitations. It has only succeeded in depleting natural resources fast enough to delay the impending collapse temporarily (Sachs, 2008). There is also the 'population optimists' who hold a contrary opinion to the pessimists, believing that rapid population growth allows economies of scale and promotes technological progress which will eventually promote growth. Finally, the 'population neutralists' contend that population itself, holding other variables constant neither has neither a positive nor a negative effect on economic growth. Contemporary empirical researches on the subject matter have either supported the pessimists o the optimists, however, the neutralists view has remained largely unsubstantiated (Hamza, 2015).

The major drivers of population growth are the rates of fertility, mortality and migration. In most cases, migration from other continents to Africa is very rare with few cases of intra-continent migration (within countries of Africa). High fertility rates translate into rapid population growth. However, demographic transition has ushered significant declines in rate of fertility and mortality in most countries in the world, except in Africa. Although there has been a decline in total fertility rates, fertility levels still remain high and the population growth rate remains unacceptably high by global standards in Africa. Africa is the continent that still has an average fertility rates of over 4.5 , characterized by a slow decline and in some cases, stalled (Odimegwu, Bamiwuye, and Adedini, 2015; Bongaarts, 2005).

High fertility and youth dependency which contribute to stagnation are common demographic features of African countries (Akintunde, et al 2013). High fertility rate impedes per- capita economic growth for both microeconomic and macroeconomic reasons. At the micro level, high fertility means less investment in the children's human capital (nutrition, health and education). At the Macro level, it puts too much pressure on national resources thereby causing the national government to spend fewer resources to improving average services (per person). A strong positive correlation is observed between poverty and fertility even within developed countries. The rich get richer, and the poor get children is how the scenario is described. Countries with high fertility rate indeed have lower growth rates of income per person. Total Fertility rate is known to have a strong statistically significant negative effect on economic growth. Thus the pattern of global population is a matter of choice through policies from the Less Developed Countries especially policies that will ensure the completion of the demographic transition by reducing Total Fertility rates in Africa (Sachs, 2008). 
Mortality rates still remain high in Africa due to poor development and poor coverage of medical facilities especially in the rural areas. Mortality rates are highest among infants, young children, and the elderly, so societies with larger number of elderly people are likely to have more deaths per 1,000 people than those where most citizens are young adults. The probability that a child will die at a given age drops through childhood and adolescence aftershe passes through the vulnerable early years, then starts to rise gradually in mid-life (Horizon, 2009).

The relationship between population growth and economic growth has been a matter of debate for over a century. The early Malthusian view was that population growth is likely to impede economic growth because it will put pressure on the available resources, thus resulting in reduction in per capita income and resources; this, in turn, will result in deterioration in quality of life. However, Contrary to the Malthusian predictions, several of the East Asian countries have been able to achieve economic prosperity and improvement in quality of life in spite of population growth. This has been attributed to the increase in productivity due to development and utilization of innovative technologies by the young educated population who formed the majority of the growing population. These countries have been able to exploit the dynamics of demographic transition to achieve economic growth by using the human resources as the engine driving the economic development; improved employment with adequate emoluments has promoted saving and investment which in turn stimulated economic growth (Pritchett, 1996).

According to the Solow model, (Solow, 1956) there are two distinct effects of population growth rate change on the output growth. In his opinion, on the one hand, an increase in the population growth rate will increase the amount of labor and thus both the absolute level of output and the steady state output growth rate. On the other hand, it will also reduce physical capital stock per worker; therefore, a decrease in productivity and in the steady state output per worker. Thus, it means that higher population growth rate will logically be detrimental to economic growth.

\section{Empirical Literature}

The nature of relationship between population growth and economic growth of countries is not empirically definitive even though theoretically it seems to be a negative effect of population on economic growth. However, the case of some countries Brazil, Russian Federation, India, China and recently South Africa (BRICS) contradicts this position as population seems to affect growth positively. Thus, there still exist discordant views on the 
Pakistan Journal of Humanities and Social Sciences, 6(4), 2018

impact of population on economic growth. Various researches have been embarked upon to reexamine the relationship using various methods and various country data, all in a bid to arrive at a single unanimous position on the subject. However, this has continued to prove elusive as one study finds a positive relationship, another finds a negative relationship. Hamza (2015); Akintunde, Olomola and Oladeji (2013); Tartiyus, Mohammed and Peter (2015); Klasen and Lawson (2007); Bloom, Canning and Malaney (1999); Prskawetz, Fent and Barthel (2007); Chang, Chu, Deale and Gupta (2015) Crist, Mora and Engelman (2017) are some of the researches empirically reviewed in this study.

Several studies have found that population growth has a negative impact on economic growth. Hamza (2015) found a negative relationship between population parameters (birth rates, death rates and net migration, with only death rate being statistically insignificant) and economic growth of developing countries. In another study, Akintunde, Olomola and Oladeji (2013); Cist, Mora and Engelman (2017) found a negative impact of population growth rate on economic growth in Sub-Sahara Africa and on food security as well as biodiversity. However, they found that life expectancy has a positive impact on economic growth on SubSahara Africa. These findings are consistent with the opinion of the pessimists about populations' impact on economic growth. Bloom Canning and Malaney (1999) in a similar study found among others that population has a strong negative impact on economic growth of Asia. However, they found on the contrary that the growth of the working age population has a positive impact on economic growth. This finding was statistically significant and persists even when instrumental variables were included to control for reverse causation in the model. They further found that population density along the coast has a positive impact while population density inland has a negative impact on population. Basu, Barik and Arokiasamy (2013) also found that growth of the share of the working population has a positive and significant impact on economic growth of BRICS. They also found that the initial level of the working age population is also significant in determining economic growth. The findings of this study are closely related to that of the study conducted by Bloom, Canning and Malaney (1999). However, these studies have not made a clear cut interaction between population and economic growth. The main issue is not the working class of the population and its impact but population in general. Essien (2016), Tartiyus, Mohammed and Peter (2015) and Nwosu, Dike and Okwara (2014) also found out that population has a positive impact on the growth potential of Nigeria. Thus, there seems to more optimistic views on population than pessimists as the review shows. However, various countries data and methodologies were 
used in the analysis. There could be methodological weaknesses which may affect the results of some studies reviewed.

Methodologically, the study of Hamza (2015) applied panel data analytical methodology on a cross section of 30 developing countries selected from Africa, Asia and Latin America for a period of 14 years (2001 -2014). The data were analyzed using panel unit root analysis, cointegration analysis, causality analysis and the random effect $t$ model. At least the study did not apply the use of Pooled OLS, and therefore the result does not carry the effect of omitted variables. However, the study did not estimate the relationship between population variables and economic growth using dynamic panels. The GMM estimators are generally consistent and asymptotically normally distributed. The study did not include population growth among its regressors to determine the impact it has on economic growth of developing countries, rather it only examine birth rates, death rates and net migration and their effect on economic growth. Akintunde, Olomola and Oladeji (2013) studied population dynamics and economic growth in Sub-Sahara Africa using dynamic panel data analysis (difference and system GMM). The study did not make use of Pooled OLS, random or fixed effects models, perhaps because the dynamic panels are better suited for studying dynamic relationship under panel data framework. The study did present vital population and economic statistics descriptively, but it failed to apply the causality test, which would have provided more insight into the dynamic relation being studied. However, there is not likelihood of bias in the result due to omitted variables since Pooled OLS was not employed in the study. Chang, Chu Deale and Gupta (2015) studied the relationship between population and economic growth using bootstrapped panel causality test between 1870 and 2013 . The study applied the bootstrapped causality test. The method of analysis is unique among other such studies as the static or dynamic estimation techniques were not applied. Thus the study can only suggest the impact of population on economic growth based on the results of the causality test. Moreover, different directions of causality were found among different countries. The study cannot be used as a basic for comparison and corroboration with other studies on the impact of population on economic growth. Bloom Canning and Malaney (1999) studied demographic change and economic growth in Asia. The study applied the use of multiple regression as well as dynamic panel analysis. The problem of bias in estimation due omitted variables was avoided as Pooled OLS was not used in the study. However, the study did not just determine the impact of population on economic growth, but it also focused on the impact of the working population on economic growth. Crist, Mora and Engelman 
Pakistan Journal of Humanities and Social Sciences, 6(4), 2018

(2017), also used descriptive statistics in the form of graphs to show the linkage between population and its impact on nature. Basu, Barik and Arokiasamy (2013) studied demographic determinants of economic growth in BRICS and selected developed countries using panel data analysis. The study used descriptive analysis in the form of tables and bar charts as well as the random and fixed effects model. The study did not use panel data analysis techniquesthe system or difference GMM in the analysis of data, analysis were basically using random and fixed effects, thus estimation bias due to omitted variables problem is avoided in the study. Other studies Essien (2016), Tartiyus, Mohammed and Peter (2015) and Nwosu, Dike and Okwara (2014) used time series analysis to determine the impact of population growth on economic growth in Nigeria. The usual problems of time series- unit root, specification error, are found in most cases. Moreover, the methodology to be adopted by this study is panel estimation technique, not time series estimation technique.

The various reviews made have revealed a common feature among the studies conducted. The studies were conducted to determine the impact of population growth on economic growth. While some of the studies were conducted on the countries of a particular sub-region, others were conducted on selected countries (developing in most cases) across the various continents or regions of the world. The methodologies used by the various studies were not far from each other, as in most cases, descriptive analyses, causality and static or dynamic panel analyses were employed. An obvious gap which this study is set out to fill is that none of these studies was carried out on the entire Africa. Thus this study will reveal the impact of population on economic growth of Africa, the poorest continent in the world and the fastest growth in continent.

\section{Theoretical Framework}

\section{A. Unified Growth Theory}

The Unified growth theory came on stage as a result of the inconsistencies of endogenous and exogenous neoclassical models of growth. The theory was advanced by Obed Galor and his associated in the year 2000. The Unified growth theory presents the transition from stagnation to growth over the course of human history in a single analytical framework, as product of transition through some stages which must be followed by countries in their growth path. The stages are; first, the epoch of Malthusian stagnation that characterized most of human history. Second, the escape from the Malthusian traps. Third, the emergence of human capital formation in the process of development. Fourth, the onset of demographic 
transition. Fifth, the origins of the contemporary era of sustained economic growth and finally, the divergence in income per capita across countries (Galor, 2012).

Like the 1960s Rostow's stages of growth models, which places countries in various stages of growth according to their observable economic characteristics, the Unified growth theory with more consideration for the Malthusian phenomenon outlined six stages in the ladder of growth of countries. The post Malthusian epoch which was achieved by several countries in Europe, took off late in Africa, Asia and Latin America, and it is still in motion in Africa today. Thus, most of the African countries have still not escaped the Malthusian Trap. The theory further states that the transition from the Malthusian trap to economic growth is brought about by gradual change in the composition of the population, and its effects on technological progress and human capital formation.

The unified growth theory is not unlike other growth theories in economics as it has also attracted wide criticisms. Perhaps it has been criticized as widely as the Malthusian theory itself, which is the framework of the theory. Nielson (2015) asserts that the Unified Growth Theory is repeatedly contradicted by data on the world economic growth and the economic growth in Western Europe. He further observes that even in the former USSR, data on GDP/ capital contradicts the theory suggesting that there was no escape from the Malthusian epoch as there was never a trap. Growth was unconstrained during the alleged but non-existent epoch of stagnation. Thus the theoretical stagnation and escape are incorrect assertions by the proponent of the Unified Growth Theory.

However, this criticism does not render the theory debunked. The theory has found credibility in the African experience of population and its related difficulties. Africa, when put in the context of the Unified growth theory seems to give the theory credibility beyond mere criticisms. This is one of the major reasons why this study adopts the theory as a theoretical framework for the study of the impact of population on economic growth of African countries. The theory aligns itself with the 'pessimist population' view. Until the completion of demographic transition in Africa, we cannot assert that there is an escape, but obviously there is an entrapment. Even after the completion of the demographic transition, population growth will not immediately stabilize itself because of an inherent tendency to increase in the population momentum (Sachs, 2008).

\section{Methodology}

This study adopted the use of descriptive statistical analysis for a comparative analysis of demographic variables between Africa and other countries as well as regions. The 
dynamic panel data models were also used for empirical analysis in the study. Due to the problem of omitted variables which may be encountered in the use of Pooled OLS, this study used dynamic models for estimation. This is to avoid problem of omitted variables in estimation which is most commonly associated with Pooled OLS. The System GMM as well as the Difference GMM was used for two step and two step with robust standard errors.

\section{A. Data}

The data used for this study were collected from the World Development Indicators database, 2015. Annual secondary data for Economic growth proxied by GDP was used as the dependent variables and regressed against Population growth (POG), Inflation rate (INF) fertility rate (FER) and crude death rate (CDR) for the period 1980 - 2015.

\section{B. Model}

The model for estimating the impact of population growth on economic growth of African countries is expressed functionally as;

$$
G D P_{i t}=\beta_{0}+\beta_{1} P O G_{i t}+\beta_{2} I N F_{i t}+\beta_{3} F E R_{i t}+\beta_{4} C D R_{i t}+\mu_{i t}
$$

Where;

$\begin{array}{lll}\text { GDP } & - & \text { Proxy for Economic Growth of cross sectional units } \\ P O G & - & \text { Population growth rate of Cross sectional units } \\ \text { INF } & - & \text { Inflation rate of cross sectional units } \\ F E R & - & \text { Fertility rate of cross sectional units } \\ \text { CDR } & - & \text { Crude death rate of cross sectional units } \\ \beta o-\beta 4 & - & \text { Regression coefficients } \\ \mu & - & \text { Random error term } \\ i & - & \text { Cross-sectional units (53 African countries) } \\ t & - & \text { Time dimension (36 years [1980 -2015]) }\end{array}$

\section{A priori Expectations}

$$
\beta_{1}<1 ; \beta_{2}<1 ; \beta_{3}<1 \text { and } \beta_{4}>1 \text {. }
$$

Thus the coefficients of Population growth rate, Inflation rate and Fertility rates are expected to be less than 1 (negative) implying a negative impact on economic growth, while the coefficient of Crude death rate is expected to be greater than 1(positive) implying a positive impact on economic growth.

\section{Results and Discussion}

The statistics of African countries on the variables Crude Death Rate (CDR), Fertility rate (FER), Gross Domestic Product (GDP), Inflation Rate (INF) and Population Growth Rate (POG) are presented in table 1. However, the study is more interested in the statistics of 
fertility rate, crude death rate and population growth rate. The average fertility rate of Africa is 5.48, African countries still maintain high rates of fertility in the world. Except Afghanistan which falls in the ranks of African countries with high fertility rates, the twenty countries with highest fertility rates are from Africa. The developed countries have adopted the replacement rate of fertility, where parents would give birth to two children to replace them (Sachs, 2005). Closely related to the fertility rate is the crude death rate index, where the mean for African countries is 13.01, which is very fair compared to those of other countries. Countries like Lithuania, Ukraine and Bulgaria have crude death rates in excess of 15.30 (UNPD, 2017),therefore, this statistic is bad for Africa as a continent, and it is believed to improve when the continents develops further. Population growth rate on the average for Africa is $2.53 \%$, which double that of the entire world (1.2\%), Latin America and Caribbean (1.2\%) and almost treble that Asia (UNDP, 2016). Africa has the largest population growth rate in the world, which is not unexpected given its high rates of fertility. The average inflation rate in Africa is 55.61, which is high for achieving a reasonable rate of economic growth, as inflation is one of the principal macroeconomic policy variables that affect economic growth (Ndambiri, Ritho, Nga'anga, Kubowon, Mairura, Nyangweso, Muiriri and Cherotwo, 2012).

Table 1: Descriptive Statistics

\begin{tabular}{|l|l|l|l|l|l|}
\hline & CDR & FER & GDP & INF & POG \\
\hline Mean & 13.0135 & 5.4862 & $2.49 \mathrm{E}+12$ & 55.615 & 2.5369 \\
\hline Median & 12.5100 & 5.7610 & $1.68 \mathrm{E}+11$ & 7.2525 & 2.643326 \\
\hline Maximum & 39.5970 & 8.4480 & $1.32 \mathrm{E}+14$ & 24411.03 & 8.354904 \\
\hline Minimum & 4.7410 & 1.4300 & 0.134317 & -35.83668 & -6.342817 \\
\hline Std. Dev. & 4.8913 & 1.4367 & $8.59 \mathrm{E}+12$ & 857.5415 & 1.102807 \\
\hline Skewness & 0.69981 & -0.7225 & 8.186002 & 26.8992 & -0.374427 \\
\hline Kurtosis & 4.1244 & 2.9031 & 87.10033 & 750.6007 & 11.58010 \\
\hline Jarque-Bera & 249.1363 & 160.8933 & 554238.5 & 38623825 & 5878.682 \\
\hline Prob. & 0.00000 & 0.00000 & 0.000000 & 0.00000 & 0.000000 \\
\hline Sum & 24140.08 & 10100.16 & $4.51 \mathrm{E}+15$ & 91765.99 & 4825.279 \\
\hline Sum sq dev. & 44357.65 & 3798.46 & $1.34 \mathrm{E}+29$ & $1.21 \mathrm{E}+09$ & 2311.965 \\
\hline Observations & 1855 & 1841 & 1812 & 1650 & 1902 \\
\hline So Co & & & &
\end{tabular}

Source: Computation using STATA 12, 2017.

\section{A. Empirical Results}

Table 2 presents the results of the Difference GMM panel data analysis. The results are presented for one step, two steps and two steps with robust standard errors. The results of the Sargan test and the Arrelano-Bond Autocorrelation test are equally presented. The Sargan test of over identifying restrictions was used to determine which instrument is valid. The Sargan statistic under one step is 1551 with a probability value of 0.0000 . Thus over 
identifying restrictions are invalid since the probability value is less than 0.05 . The Sargan statistic under two steps is 48.53384 with a probability value of 1.000 , which means that instrument is valid now. Moreover, the result of the Arrelano-Bond autocorrelation test suggests that there is no autocorrelation as the probabilities of the autocorrelation statistics $\mathrm{AR}(1)$ and $\mathrm{AR}(2)$ suggests. by the coefficients of the variables under two step, the coefficient of the lag dependent being .9477844 is statistically significant in determining the dependent variable. The coefficient of $\mathrm{Ln} \mathrm{POG}_{\text {it }}$ is .0725926 which suggests that if population growth of African countries should increase by 1 unit, economic growth of African countries will increase by.0725926 units. The coefficient of inflation $\mathrm{Ln} \mathrm{INF}_{\text {it }}$ being .1263161 suggests that if inflation in Africa should increase by 1 unit, economic growth of Africa will increase by .1263161 units. The slope coefficient of fertility being -.704986 suggests that if fertility should increase by 1 unit in Africa, economic growth will decrease by - .704986 units. Thus fertility has a negative and statistically significant impact on economic growth of African countries. Finally, the coefficient of crude death rate suggests that if crude death rate should increase by 1 unit, economic growth of African countries will increase by .1326327 units. Thus all the variables modeled are statistically significant in explaining the economic growth of African countries.

Table 2: Results of Difference GMM Panel Model

\begin{tabular}{|l|c|c|c|}
\hline & One Step & Two Step & $\begin{array}{c}\text { Two step with robust } \\
\text { standard errors }\end{array}$ \\
\hline LnGDPit-1 & $.9477844(0.000)$ & $.944578(0.000)$ & $.944578(0.001)$ \\
\hline Ln POG it & $.0725926(0.010)$ & $.0692274(0.000)$ & $.0692274(0.967)$ \\
\hline Ln INF it & $.1263161(0.000)$ & $.1226083(0.000)$ & $.1226083(0.824)$ \\
\hline Ln FER it & $-.704986(0.000)$ & $-.6678379(0.000)$ & $-.6678379(0.947)$ \\
\hline Ln CDR it & $.1326327(0.070)$ & $.0814688(0.006)$ & $.0814688(0.988)$ \\
\hline Sargan Test & $1551(0.0000)$ & $48.53384(1.000)$ & - \\
\hline AR (1) & $-11.268(0.0000)$ & $-2.1579(0.0309)$ & $-.80745(0.4194)$ \\
\hline AR (2) & $-1.5719(0.1160)$ & $-.90541(0.3652)$ & $-.64512(0.5189)$ \\
\hline
\end{tabular}

Source: Computation using STATA 12, 2017

Table 3 presents the results of the System GMM panel data analysis. The results are presented for one step, two steps and two steps with robust standard errors. The results of the Sargan test and the Arellano-Bond Autocorrelation test are equally presented. The Sargan test of over identifying restrictions was used to determine which instrument is valid. The Sargan statistic under one step is 2040.38 with a probability value of 0.0000 . Thus over identifying restrictions are invalid since the probability value is less than 0.05 . The Sargan statistic under two step is 50.45574 with a probability value of 1.000 , which means that instrument is valid 
now. By the coefficients of the variables under two step, the coefficient of the lag dependent being .9802237is statistically significant in determining the dependent variable. The coefficient of $\mathrm{Ln} \mathrm{POG}_{\mathrm{it}}$ is .1699009 which suggests that if population growth of African countries should increase by 1 unit, economic growth of African countries will increase by.1699009 units. The coefficient of inflation $\mathrm{Ln} \mathrm{INF}_{\mathrm{it}}$ being .1859533 suggests that if inflation in Africa should increase by 1 unit, economic growth of Africa will increase by .1859533 units. The slope coefficient of fertility being -.7508208 suggests that if fertility should increase by 1 unit in Africa, economic growth will decrease by -.7508208 units. Thus fertility has a negative and statistically significant impact on economic growth of African countries. Finally, the coefficient of crude death rate suggests that if crude death rate should increase by 1 unit, economic growth of African countries will increase by .6492645 units. Thus all the variables modeled are statistically significant in explaining the economic growth of African countries.

Table 3: Results of System GMM panel models

\begin{tabular}{|l|c|c|c|}
\hline & One Step & Two Step & $\begin{array}{c}\text { Two step with robust } \\
\text { standard errors }\end{array}$ \\
\hline Ln gdpit-1 & $.9781199(0.000)$ & $.9802237(0.000)$ & $.9802237(0.000)$ \\
\hline Ln POG it-1 & $.191002(0.000)$ & $.1699009(0.000)$ & $.1699009(0.935)$ \\
\hline Ln INF it-1 & $.1959199(0.000)$ & $.1859533(0.000)$ & $.1859533(0.675)$ \\
\hline Ln FER it-1 & $-.943109(0.000)$ & $-.7508208(0.000)$ & $-.7508208(0.945)$ \\
\hline Ln CDR it-1 & $.7022298(0.000)$ & $.6492645(0.000)$ & $.6492645(0.899)$ \\
\hline Sargan Test & $2040.38(0.0000)$ & $50.45574(1.000)$ & - \\
\hline AR (1) & - & $-2.5653(0.0103)$ & $-1.0814(0.2795)$ \\
\hline AR (2) & - & $-1.1789(0.2384)$ & $-.87991(0.3789)$ \\
\hline
\end{tabular}

Source: Computation using STATA 12, 2017.

The results of the Difference GMM and the System GMM reveal that the population growth rate of Africa has a positive impact on the economic growth of the continent. Population growth was observed to have a positive and statistically significant impact on economic growth, while fertility rate has a negative and statistically significant impact on population growth. This finding is consistent with the results of the finding of Tartiyus, Inuwa and Peter (2015); Essien (2016) and Nwosu, Dike and Okwara (2014) on the impact of population growth on economic growth in Nigeria. Kothare (1999) also found out that India's population has a positive and significant impact on the economic growth of India. Basu, Barik and Arokkiasamy (2013), studying the demography of BRICS and economic growth also found that population of the working population has a positive impact on the growth potentials of BRICS. In contrast, Hamza (2015), Akintunde, Omomola and Oladeji (2013) 
and Bloom, Canning and Malaney (1999) found negative impact of population on economic growth of developing countries, Sub-Sahara Africa and Asia.

\section{Conclusion and policy Recommendations}

The conclusion of this study is that Africa has got to benefit from demographic dividends as its population was found to have a positive impact on its economic growth. Africa is a backward region and it has not been putting available resources to optimal use for enhancing economic growth. Africa just like the countries of BRICS has benefits to reap from its population before it reaches the point of diminishing returns to the growth of the continent. Therefore the paper recommends that:

(i) Africa should adopt and implement pragmatic policy measures that will enhance the productivity of its fast growing population so as to enhance the rate of economic growth in the continent. 


\section{References}

Akintunde, T.S., Omolola, A.P. and Oladeji, I.S.(2013). Population Dynamics and Economic Growth in Sub-Saharan Africa.Journal of Economics and Sustainable Development 4(13): $147-158$.

Basu,T., Barik, D. and Arokiasamy, P. (2013). Demographic determinants of economic growth in BRICS and selected developed countries. Presented in XXVII IUSSP International Population Conference at BEXCO, Busan, Republic of Korea.

Bloom, D.E., Canning, D. and Malaney, P.N. (1999). Demographic Change and Economic Growth in Asia. Centre for International Development, Harvard University, Working Paper No. 15

Bongaarts, J.(2005). The causes of stalling fertility transitions. Policy Research Division, population Council. Working papers No. 204.

Bongaarts, J. \& O'Niell, B.C.(2018). Global warming Policy: Is population left out in the cold? Science 361(6403):650-652.doi:10:1126/scienceaat8680.

Chang,T., Chu, H., Deale, F.W., and Gupta, R. (2014). The Relationship between Population Growth and Economic Growth Over 1870-2013: Evidence from a Bootstrapped Panel-Granger Causality Test. University of Pretoria, Department of Economics working paper 2014-31.

Crist, E., Mora, C. \& Engelman, R. (2017). The interaction of human population, food production and biodiversity protection. Science 356(6335):260-264.

Essien, E. B.(2016) Population growth and Economic performance In Nigeria (1981-2014). Turkish Economic Review 3(1) 1-17

Galor, O. (2012). Unified growth Theory: From Stagnation to Growth. Retrieved May 10, 2017 from www.https://press.princeton.edu/titles/9477.html.

Hall, C. Dawson,T.P., Macdiarmid, J.I., Matthews, R.B., \& Smith, P.(2017). The Impact of population growth and climate change on food security in Africa: Looking ahead to 2050. International Journal of Agricultural Sustainability 15(2):124 -135.

Hamza, L. (2015).Panel Data Analysis of Population Growth and It Implication on Economic Growth of Developing Countries. Proceedings of the International Symposium on Emerging Trends in Social Science Research. Chennai-India, paper Id C509

Horizon, (2009). Population Growth and Food insecurity. What does the future hold? Future issues for development. Pilot issue (2009).

Klasen, S., and Lawson, D.(2007).The impact of population growth on economic growth and poverty reduction in Uganda.Diskussionsbeiträge aus dem Volkswirtschaftlichen Seminar der Universität Göttingen, No. 133

Lozeau, B. (2007).The Effects of Population Growth on Economic Performances in China and India. Brussels Journal of International Studies 4(1):1-8

Mekonnen, D. (2011). Fertility in East Africa Countries. The role of socio-economic factors in East Africa 1998 - 2010. Lund University School of Economics and Management. An Unpublished Master Programme Thesis in Economic Demography.

Ndambiri H. K., Ritho C., Ng'ang'a S. I., Kubowon, P. C., Mairura F.C., Nyangweso P.M., Muiruri E. M. \& Cherotwo F. H.(2012).Determinants of Economic growth in SubSahara Africa. A Panel data Approach. International Journal of Economics and Management Sciences 2(2):18-24.

Nielsen, R.W. (2015). Unified growth theory contradicted by the economic growth of the former USSR. Retrieved May $7^{\text {th }} 2017$ from https://arxiv.org/pdf/1601.04686. 
Nwosu, C. Dike, A.O. and Okwara, K.K. (2014).The Effects of Population Growth on Economic Growth in Nigeria. The International Journal of Engineering and Science (IJES) 3(11):7-18

Odimegwu, C. Bamiwuye, O.S., and Adedini, S.A. (2015). Gender-based violence as a new proximate Determinant of fertility in sub-Saharan Africa. Southern African Journal of Demography 16(1):87 -120.

Pritchett, L. (1996). Population Growth, Factor Accumulation and Productivity. Policy Research Working paper 1567. World Bank. Poverty and Human Resources Division.

Prskawetz, A. Fent, T. and Barthel, W. (2007). The Relationship between demographic change and economic growth in the EU. Institute of Demography. Research Report 32.

Sachs, J. (2008). Common Wealth: Economics for a crowded planet. New York: Penguin Books.

Solow, R. M. (1956). A Contribution to the Theory of Economic Growth. The Quarterly Journal of Economics 70, No. 1: 65.

Tartiyus, E.H., Mohammed I.D., and Peter, A. (2015). The impact of population growth on economic growth of Nigeria (1980-2010). IOSR Journal of humanities and Social Sciences 20 (4):115 -123.

UNDP(2015). World Population Data Sheet 2016. Population reference Bureau. Retrieved $12^{\text {th }}$ May 2017 from www.prb.org/Publications/Datasheets/2016/2016-worldpopulation-data-sheet.aspx

United Nations. (2015). World population prospects: The 2015 revision, key findings and advance tables (Working Paper No. ESA/ P/WP.241). New York, NY: The Department of Economic and Social Affairs of the United Nations. 